\title{
DFT calculations of the structure and stability of copper clusters on $\mathrm{MoS}_{2}$
}

\author{
Cara-Lena Nies and Michael Nolan
}

\author{
Full Research Paper \\ Address: \\ Tyndall National Institute, University College Cork, Lee Maltings, Dyke \\ Parade, Cork, T12 R5CP, Ireland \\ Email: \\ Michael Nolan* - michael.nolan@tyndall.ie \\ * Corresponding author \\ Keywords: \\ copper (Cu); density functional theory (DFT); 2D materials; \\ molybdenum disulfide $\left(\mathrm{MoS}_{2}\right)$; thin film nucleation
}

\author{
doi:10.3762/bjnano.11.30 \\ Received: 08 November 2019 \\ Accepted: 11 February 2020 \\ Published: 26 February 2020 \\ Associate Editor: J. Frommer
}

Beilstein J. Nanotechnol. 2020, 11, 391-406.

(C) 2020 Nies and Nolan; licensee Beilstein-Institut.

License and terms: see end of document.

\begin{abstract}
Layered materials, such as $\mathrm{MoS}_{2}$, are being intensely studied due to their interesting properties and wide variety of potential applications. These materials are also interesting as supports for low-dimensional metals for catalysis, while recent work has shown increased interest in using 2D materials in the electronics industry as a $\mathrm{Cu}$ diffusion barrier in semiconductor device interconnects. The interaction between different metal structures and $\mathrm{MoS}_{2}$ monolayers is therefore of significant importance and first-principles simulations can probe aspects of this interaction not easily accessible to experiment. Previous theoretical studies have focused particularly on the adsorption of a range of metallic elements, including first-row transition metals, as well as Ag and Au. However, most studies have examined single-atom adsorption or adsorbed nanoparticles of noble metals. This means there is a knowledge gap in terms of thin film nucleation on 2D materials. To begin addressing this issue, we present in this paper a first-principles density functional theory (DFT) study of the adsorption of small $\mathrm{Cu}_{n}(n=1-4)$ structures on $2 \mathrm{D} \mathrm{MoS} 2$ as a model system. We find on a perfect $\mathrm{MoS}_{2}$ monolayer that a single $\mathrm{Cu}$ atom prefers an adsorption site above the Mo atom. With increasing nanocluster size the nanocluster binds more strongly when $\mathrm{Cu}$ atoms adsorb atop the $\mathrm{S}$ atoms. Stability is driven by the number of $\mathrm{Cu}-\mathrm{Cu}$ interactions and the distance between adsorption sites, with no obvious preference towards $2 \mathrm{D}$ or 3D structures. The introduction of a single $\mathrm{S}$ vacancy in the monolayer enhances the copper binding energy, although some $\mathrm{Cu}_{n}$ nanoclusters are actually unstable. The effect of the vacancy is localised around the vacancy site. Finally, on both the pristine and the defective $\mathrm{MoS}_{2}$ monolayer, the density-ofstates analysis shows that the adsorption of $\mathrm{Cu}$ introduces new electronic states as a result of partial $\mathrm{Cu}$ oxidation, but the metallic character of $\mathrm{Cu}$ nanoclusters is preserved.
\end{abstract}

\section{Introduction}

Since the successful exfoliation of monolayers of graphene by Novoselov et al., 2D materials have gained a large interest in a variety of research areas [1]. These include catalysis [2,3], photonics [4,5], batteries [6], sensors [7,8] and semiconductors and electronics [9-11]. More recently, 2D materials have been explored as copper diffusion barriers in CMOS interconnect 
structures [12-15]. Furthermore, to enable the use of 2D materials in technology applications, processes have been developed to grow 2D materials via chemical vapour deposition (CVD) $[16,17]$ and atomic layer deposition (ALD) $[18,19]$. The films prepared via thin film deposition were comparable in performance to materials obtained via exfoliation. However, the scalability of CVD and ALD processes makes 2D materials grown via these methods more realistic for a wider range of applications [4].

Transition metal dichalcogenides (TMDs) are of particular interest as they exhibit a large variety of properties. TMDs such as $\mathrm{MoS}_{2}$ are intrinsic semiconductors, unlike graphene, and have thus garnered significant interest in the electronics industry [4]. Often, the properties of the monolayer are different from those of the bulk materials. For example, $\mathrm{MoS}_{2}$ has an indirect bandgap in its bulk structure, while it exhibits a direct bandgap as a monolayer [20]. The extensive interest in $\mathrm{MoS}_{2}$ can be in part attributed to its favourable properties compared to graphene, as well as the fact that it occurs naturally [21].

There have been numerous computational studies of $\mathrm{MoS}_{2}$ and other 2D materials $[9,22,23]$, many of which have examined the adsorption of, or doping with, various elements including transition metals [3,9,24-28], alkali and alkaline-earth metals [2931] as well as non-metals such as H, B, C, O and N [31]. Work involving atom adsorption on $2 \mathrm{D}$ materials can generally be divided into two categories: single-atom adsorption [26,29-31] and adsorption of larger structures such as nanoparticles [25] or metal chains [24].

Studies of single-atom adsorption have focused on screening the stability of a range of elements at TMD monolayers. As an example, Wang et al. [26] studied the adsorption energy, stable geometries, magnetic and electronic properties of first-row transition metal atoms adsorbed on a monolayer of $\mathrm{MoS}_{2}$. All metals studied adsorb strongly on the $\mathrm{MoS}_{2}$ monolayer, except for $\mathrm{Zn}$, whereby the adsorption energy depends on the identity of the adsorbed element; this is proposed to be related to the number of $\mathrm{d}$ electrons. In general, the atoms prefer to adsorb above a Mo atom, however Sc, Ti and Mn prefer a hollow site inside the Mo-S hexagon. Overall, it was concluded that the band structure and magnetic properties of $2 \mathrm{D} \mathrm{MoS} 2$ can be modified by adsorbing different transition metals [26].

Li et al. [29] and Makaremi et al. [31] also examined adsorption of a variety of elements including alkali and alkaline-earth metals as well as non-metals such as $\mathrm{H}, \mathrm{C}$ and $\mathrm{O}$ on $\mathrm{MoS}_{2}$ and $\mathrm{C}_{3} \mathrm{~N}$. Both studies aimed to screen different ways in which the monolayers could be functionalised, depending on the type of atom that is adsorbed. Li et al. [29] find that normally semicon- ducting $\mathrm{MoS}_{2}$ monolayers can be tuned to exhibit metallic or semi-metallic behaviour depending on the adatom type. All atoms studied had favourable adsorption energies. $\mathrm{Mg}$ had the weakest interaction with a computed adsorption energy of $0.60 \mathrm{eV}$, while Mn had the strongest interaction, with a computed binding energy of $6.57 \mathrm{eV}$. The preferred adsorption site depends on the adsorbed atom. The majority of atoms prefers to adsorb above Mo, including $\mathrm{Cu}, \mathrm{C}$ and $\mathrm{Mg}$. $\mathrm{Mn}$ and $\mathrm{Ag}$ prefer to adsorb at a hollow site of the Mo-S hexagon, and Au and $\mathrm{O}$ adsorb atop the $\mathrm{S}$ atoms. Similarly, Makerami et al. [31] find that the functionalisation of semiconducting $\mathrm{C}_{3} \mathrm{~N}$ monolayers with non-metallic and semi-metallic elements leads to metallic behaviour. Interestingly, not all metallic adatoms were found to induce metallic behaviour. Metals such as $\mathrm{Mg}, \mathrm{Cr}$ and $\mathrm{Zn}$ are unable to alter the surface from semiconducting to metallic. This selective alteration of the electronic properties through functionalisation makes 2D monolayers attractive candidates for various applications, such as photocatalysis, sensors and electronic devices.

Other work from Ersan et al. [30] focused on adsorption structures of Li at Se-doped $\mathrm{MoS}_{2}$, to study the suitability of the system for application in Li-ion batteries. $\mathrm{Li}$ adatoms prefer to adsorb above an Mo atom in the monolayer, and cause the system to become metallic once adsorbed. External strain was found to strongly modify the binding energy, with binding decreasing as tensile strain increases. While Li can diffuse through the monolayer, the activation energy required is greater than $1 \mathrm{eV}$ and increases with decreasing Se content. Investigation of on-surface diffusion showed that the magnitude of the activation energies is suitable for the targeted battery applications [30].

Studies of the adsorption of larger structures include the adsorption of $1 \mathrm{D}$ metal chains of $\mathrm{Cu}, \mathrm{Ag}$ and $\mathrm{Au}$ [24] on a monolayer of graphene, in which two different conformations of metal chains, namely zig-zag and armchair, are studied. The metal chains physisorb onto the monolayer, and calculations using different van der Waals (vdW) corrections show that the adsorption is driven by vdW interactions. The metal chains prefer to adsorb in the armchair conformation and cause a break of the hexagonal symmetry of graphene. Despite slightly contradictory results depending on the computational setup, the authors conclude that the adsorption of noble metal chains allows for a small opening of the bandgap of graphene, although they are unable to interpret the exact mechanism by which this occurs. The adsorption of 29 atom nanoparticles of $\mathrm{Cu}, \mathrm{Ag}$ and $\mathrm{Au}$ on a $\mathrm{MoS}_{2}$ monolayer is presented by Rawal et al. [25] to study the effect of defects in $\mathrm{MoS}_{2}$ on the catalytic activity of the supported nanoparticles. They observe that the magnitude of binding energy and charge transfer follows the 
trend $\mathrm{Cu}>\mathrm{Ag}>\mathrm{Au}$. On the pristine surface the binding energies of the nanoparticles are $5.4 \mathrm{eV}$ for $\mathrm{Cu}, 4.2 \mathrm{eV}$ for $\mathrm{Ag}$ and $4.5 \mathrm{eV}$ for $\mathrm{Au}$. The presence of a complete row of sulfur vacancies enhances the adsorption energy of the nanoparticles for all three metals, increasing it to $7.1 \mathrm{eV}, 7.0 \mathrm{eV}$ and $6.0 \mathrm{eV}$ for $\mathrm{Cu}$, $\mathrm{Ag}$ and $\mathrm{Au}$, respectively. It also increases the charge transfer from the nanoparticle to the $\mathrm{MoS}_{2}$ monolayer by approximately 1 electron for $\mathrm{Cu}$ and $\mathrm{Ag}$ and by 0.6 electrons for $\mathrm{Au}$. Studying the adsorption and dissociation of $\mathrm{O}_{2}$ on the nanoparticle demonstrated that the $\mathrm{MoS}_{2}$ support improves the catalytic activity of the nanoparticles, compared to an unsupported nanoparticle, in particular when the monolayer is defect-rich.

$\mathrm{MoS}_{2}$ is known to be naturally high in defects $[21,32]$, in particular $\mathrm{S}$ vacancies. It has been predicted that $\mathrm{S}$ vacancies in a $\mathrm{MoS}_{2}$ monolayer are most stable when they occur in a row, with a decrease in the vacancy formation energy as the number of vacancies increases [2]. Experimental methods for controlling the formation of sulfur vacancies in the $\mathrm{MoS}_{2}$ monolayer have also been developed [33], and this would allow for the targeted use of $\mathrm{S}$ vacancies to enhance desired properties such as adsorption energy.

In this study we aim to fill the gap in the literature between the adsorption of single $\mathrm{Cu}$ atoms and the adsorption of larger structures from the publications discussed above. We choose the $\mathrm{Cu}-\mathrm{MoS}_{2} \mathrm{ML}$ system due to its potential significance for the electronics industry as a copper diffusion barrier [12-15]. Studying small $\mathrm{Cu}_{n}(n=1-4)$ structures allows us to investigate the first stages in the nucleation of a $\mathrm{Cu}$ film on $\mathrm{MoS}_{2}$ monolayers, as well as the fundamental copper-TMD interactions, and thus gain significant insights into the range of stable configurations for $\mathrm{Cu}$ adsorption on $\mathrm{MoS}_{2}$. In addition, we investigate the effect of a single $\mathrm{S}$ vacancy on the adsorption energy and geometry of single $\mathrm{Cu}$ adatoms and the $\mathrm{Cu}_{4}$ clusters. The results of this investigation show that the stability of small $\mathrm{Cu}_{n}$ clusters on a $\mathrm{MoS}_{2} \mathrm{ML}$ is driven mainly by $\mathrm{Cu}-\mathrm{Cu}$ interactions and not dependent on whether the cluster is $2 \mathrm{D}$ or $3 \mathrm{D}$. Further, the density-of-states (DOS) analysis shows the emergence of mid-gap states, indicating that the system is changing from semiconducting to metallic as $\mathrm{Cu}$ atoms are adsorbed, making it suitable for application as a $\mathrm{Cu}$ diffusion barrier.

\section{Computational Methods}

All calculations, for bulk $\mathrm{MoS}_{2}$ and the 2D monolayer, were carried out with density functional theory (DFT) using the Vienna ab initio simulation package (VASP) version 5.4 [34]. It uses $3 \mathrm{D}$ periodic boundary conditions and the spin-polarized generalized gradient approximation (GGA) using the Perdew-Burke-Ernzerhof (PBE) approximation to the exchange-correlation functional [35]. The valence electrons are described explicitly using a plane wave basis set with an energy cut-off of $450 \mathrm{eV}$. The valence electron configurations used for this study are $\mathrm{Mo}=5 \mathrm{~s}^{1} 4 \mathrm{~d}^{5}, \mathrm{~S}=3 \mathrm{~s}^{2} 3 \mathrm{p}^{4}$ and $\mathrm{Cu}=4 \mathrm{~s}^{1} 3 \mathrm{~d}^{10}$. The core-valence electron interactions are described using the projector augmented wave potential (PAW) [36]. In the geometry relaxation calculations, all forces acting on the atoms were converged to within $0.02 \mathrm{eV} / \AA$. The bulk structure of $\mathrm{MoS}_{2}$ used in this study was chosen from the "Materials Project" database [37]. The bulk material contains two layers of $\mathrm{MoS}_{2}$. The geometry was then optimised by relaxing cell volume, cell shape and ionic position simultaneously, using an energy cutoff of $600 \mathrm{eV}$, as well as a Monkhorst-Pack K-point sampling grid of $(6 \times 6 \times 12)$. The computed equilibrium lattice parameters for this setup are $a=3.16 \AA, b=3.05 \AA, c=12.29 \AA$ and $\alpha=\beta=90.00^{\circ}, \gamma=63.65^{\circ}$. To create a model for the $\mathrm{MoS}_{2}$ monolayer (ML), the bottom layer was removed and the supercell was expanded five times in the $\mathrm{MoS}_{2}$ plane to create the $(5 \times 5)$ supercell shown below in Figure $1 \mathrm{~A}$. The ML supercell and all models of $\mathrm{Cu}$ adsorption were generated using the atomic simulation environment (ASE) package [38]. The atomic charges were computed from the Bader charge partitioning scheme $[39,40]$.

To understand the binding of $\mathrm{Cu}$ to the $\mathrm{MoS}_{2}$ monolayer, three different energies were computed.

1. Binding energy per $\mathrm{Cu}$ atom:

$$
E_{\text {bind } / \text { atom }}=\frac{\left(E_{\text {total }}-E_{\text {monolayer }}-n E_{\mathrm{Cu}_{-} \text {atom }}\right)}{n}
$$

$E_{\text {total }}$ is the total energy of the relaxed $\mathrm{Cu}_{n}(n=1-4)$ adsorbed on $\mathrm{MoS}_{2}$. The energy of a single gas phase $\mathrm{Cu}$ atom $\left(E_{\mathrm{Cu} \_ \text {atom }}\right)$ is multiplied by $n$, the number of $\mathrm{Cu}$ atoms in adsorbed $\mathrm{Cu}_{n}$.

2. Binding energy with reference to a free $\mathrm{Cu}_{n}$ cluster:

$$
E_{\text {bind }}=E_{\text {total }}-E_{\text {monolayer }}-E_{\mathrm{Cu}_{-} \text {cluster }}
$$

where $E_{\mathrm{Cu}_{-} \text {cluster }}$ is the energy of the most favourable $\mathrm{Cu}_{n}$ nanocluster structure in vacuum. For two atoms, this is a $\mathrm{Cu}_{2}$ dimer, for three atoms it is a triangle and for four atoms it is a tetrahedral configuration.

\section{Addition energy:}

$$
E_{\text {add }}=E_{\text {total }}-E_{\text {monolayer }+(n-1) \mathrm{Cu}}-E_{\mathrm{Cu}_{-} \text {atom }}
$$

where $n$ is the number of $\mathrm{Cu}$ atoms. This models adding a $\mathrm{Cu}$ atom to an existing adsorbed cluster with $(n-1) \mathrm{Cu}$ atoms. 
For the calculations involving $\mathrm{MoS}_{2}$ with an S vacancy, the vacancy formation energy was calculated based the reaction $\mathrm{H}_{2}+\mathrm{MoS}_{2} \rightarrow \mathrm{MoS}_{2-x}+\mathrm{H}_{2} \mathrm{~S}$, where $x$ indicates that $\mathrm{S}$ vacancies are present. The vacancy formation energy is then calculated as:

$$
E_{\text {form }}=\left(E_{\mathrm{MoS}_{2-x}}+E_{\mathrm{H}_{2} \mathrm{~S}}\right)-\left(E_{\mathrm{MoS}_{2}}+E_{\mathrm{H}_{2}}\right)
$$

In this case, the computed vacancy formation energy is $-6.16 \mathrm{eV}$

\section{Results and Discussion Cu adsorption}

Three different adsorption sites for a single atom, denoted as $\mathbf{1}$, 2 and 3, are present on the $\mathrm{MoS}_{2}$ monolayer, as shown in Figure $1 \mathrm{~A}$. Site $\mathbf{1}$ has a $\mathrm{Cu}$ atom adsorbed directly atop a $\mathrm{S}$ atom. Site $\mathbf{2}$ has $\mathrm{Cu}$ binding to three $\mathrm{S}$ atoms directly above an Mo atom and site $\mathbf{3}$ has $\mathrm{Cu}$ binding to three $\mathrm{S}$ atoms, but with no Mo atom underneath.
To investigate how $\mathrm{Cu}$ begins to nucleate on a monolayer of $\mathrm{MoS}_{2}$, we start by adsorbing small $\mathrm{Cu}_{n}(n=1-4)$ species on a $\mathrm{MoS}_{2}$ monolayer. All binding energies for the different structures calculated from Equation 1 are shown in Table 1. Binding energies calculated with Equation 2 are shown in Table 2 and addition energies are shown in Table 3.

In the $2 \mathrm{D}$ adsorption structures all $\mathrm{Cu}$ atoms are bound to the $\mathrm{MoS}_{2} \mathrm{ML}$ while in the 3D adsorption structures at least one of the $\mathrm{Cu}$ atoms is not bound to $\mathrm{MoS}_{2}$. All relaxed $\mathrm{Cu}_{n}(n=1-4)$ geometries with one, two, three and four $\mathrm{Cu}$ atoms are shown in Figure 1, Figure 2, Figure 3 and Figure 4, respectively. The binding energies shown in these images are the binding energies per atom from Equation 1.

When a single $\mathrm{Cu}$ atom adsorbs at each of the three adsorption sites, $\mathrm{Cu}$ binds exothermically with adsorption energies of $-0.81,-1.32$ and $-1.18 \mathrm{eV}$ at sites $\mathbf{1}, \mathbf{2}$ and $\mathbf{3}$, respectively. Site $\mathbf{2}$ is the most favourable site for a single $\mathrm{Cu}$ atom. This is most likely due to the particular geometry, as it is a continuation of

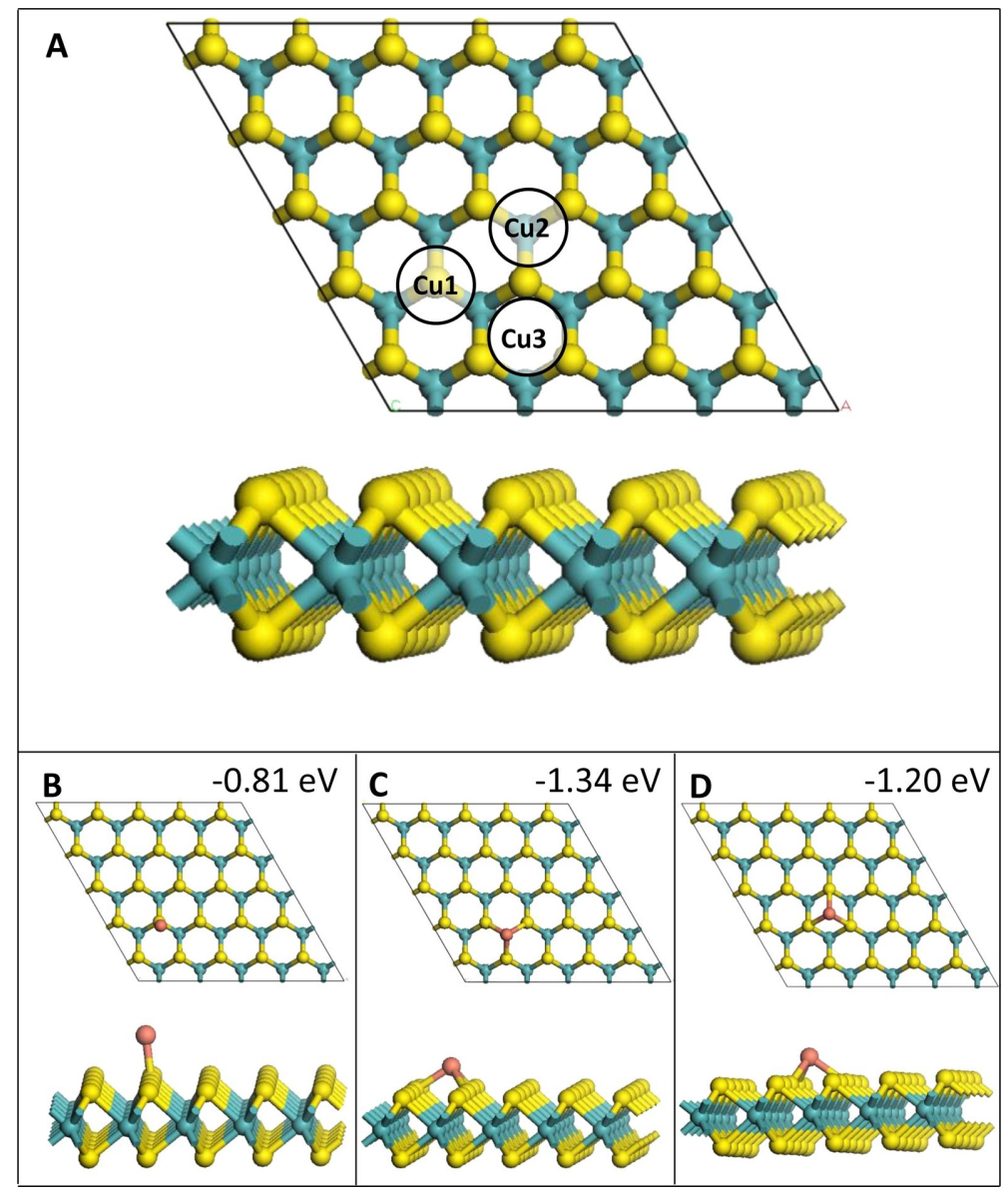

Figure 1: (A) Adsorption sites on a $\mathrm{MoS}_{2}$ monolayer. (B-D) Relaxed structures after adsorption of one $\mathrm{Cu}$ atom on the monolayer at sites 1, 2 and $\mathbf{3}$, respectively. Yellow $=\mathrm{S}$, teal $=\mathrm{Mo}$, orange $=\mathrm{Cu}$. 


\begin{tabular}{|c|c|c|c|c|}
\hline \multirow{2}{*}{$\begin{array}{l}\text { number } \\
\text { of } \mathrm{Cu} \\
\text { atoms }\end{array}$} & \multirow{2}{*}{$\begin{array}{l}\text { adsorption } \\
\text { configuration }\end{array}$} & \multicolumn{3}{|c|}{$E_{\text {bind }} /$ atom $[\mathrm{eV}]$} \\
\hline & & site 1 & site 2 & site 3 \\
\hline 1 & - & -0.81 & -1.32 & -1.18 \\
\hline \multirow[t]{3}{*}{2} & neighbouring & -0.84 & -1.54 & -1.58 \\
\hline & separated & -0.79 & -1.34 & -1.25 \\
\hline & non-equivalent sites & -1.09 & -1.00 & -1.33 \\
\hline \multirow[t]{4}{*}{3} & line & -1.34 & -1.47 & - \\
\hline & off-set & -0.82 & -1.47 & - \\
\hline & triangle & -0.85 & -1.56 & -1.64 \\
\hline & 3D triangle & -1.85 & -1.84 & -1.80 \\
\hline \multirow[t]{4}{*}{4} & line & -1.41 & -1.48 & -1.35 \\
\hline & rhombus & -2.01 & -1.87 & -1.31 \\
\hline & 3D rectangle & -1.87 & -1.87 & -1.77 \\
\hline & tetrahedral & -1.98 & -1.86 & -1.83 \\
\hline
\end{tabular}

the $\mathrm{MoS}_{2}$ structure, with $\mathrm{Cu}$ on a Mo site (see Figure 1C). This order of stability for single-atom adsorption matches results previously published by Li et al. [29] and Wang et al. [26] for $\mathrm{Cu}$ adsorption on $\mathrm{MoS}_{2}$.

Two $\mathrm{Cu}$ adatoms were adsorbed in three different configurations, i.e., as a $\mathrm{Cu}_{2}$ species with each $\mathrm{Cu}$ atom on an equivalent site, as two separated $\mathrm{Cu}$ adatoms and at neighbouring but non-
Table 2: Computed binding energies for $\mathrm{Cu}_{1}, \mathrm{Cu}_{2}, \mathrm{Cu}_{3}$ and $\mathrm{Cu}_{4}$ on $\mathrm{MoS}_{2}$ for different atom configurations from Equation 2. For the "nonequivalent" configurations of $\mathrm{Cu}_{2}$, the column "site 1" has atoms at sites $\mathbf{1}$ and $\mathbf{2}$, "site $\mathbf{2}$ " has atoms at $\mathbf{1}$ and $\mathbf{3}$ and "site $\mathbf{3}$ " has atoms at $\mathbf{2}$ and 3.

\begin{tabular}{|c|c|c|c|c|}
\hline \multirow{2}{*}{$\begin{array}{l}\text { number } \\
\text { of } \mathrm{Cu} \\
\text { atoms }\end{array}$} & \multirow{2}{*}{$\begin{array}{l}\text { adsorption } \\
\text { configuration }\end{array}$} & \multicolumn{3}{|c|}{$E_{\text {bind }}[\mathrm{eV}]$} \\
\hline & & site 1 & site 2 & site 3 \\
\hline 1 & - & -0.81 & -1.32 & -1.18 \\
\hline \multirow[t]{3}{*}{2} & neighbouring & -0.88 & -2.27 & -2.36 \\
\hline & separated & -0.77 & -1.88 & -1.69 \\
\hline & non-equivalent sites & -1.38 & -1.20 & -1.85 \\
\hline \multirow[t]{4}{*}{3} & line & -1.08 & -1.46 & - \\
\hline & off-set & 0.49 & -1.45 & - \\
\hline & triangle & 0.39 & -1.74 & -1.96 \\
\hline & 3D triangle & -2.59 & -2.59 & -2.46 \\
\hline \multirow[t]{4}{*}{4} & line & -1.63 & -1.92 & -1.41 \\
\hline & rhombus & -4.04 & -3.47 & -1.24 \\
\hline & 3D rectangle & -2.43 & -3.48 & -3.06 \\
\hline & tetrahedral & -3.92 & -3.43 & -3.31 \\
\hline
\end{tabular}

equivalent sites. At site $\mathbf{1}$, whether the $\mathrm{Cu}$ atoms adsorb as a $\mathrm{Cu}_{2}$ or as two separated adatoms makes little difference for the stability; the difference in the binding energy is only $0.05 \mathrm{eV}$. The addition energy of the second $\mathrm{Cu}$ atom is similar to the binding energy in both cases, indicating that adding a second atom yields approximately the same energy gain as the adsorption of the first atom. For the adsorption of two $\mathrm{Cu}$ atoms at sites 2 and $\mathbf{3}$ on the $\mathrm{MoS}_{2} \mathrm{ML}$, it is more favourable by up to

\begin{tabular}{|c|c|c|c|c|}
\hline \multirow[t]{2}{*}{ number of $\mathrm{Cu}$ atoms } & \multirow[t]{2}{*}{ configuration } & \multicolumn{3}{|c|}{$E_{\text {add }}[\mathrm{eV}]$} \\
\hline & & site 1 & site 2 & site 3 \\
\hline \multirow[t]{3}{*}{2} & neighbouring & -0.87 & -1.75 & -1.98 \\
\hline & separated & -0.77 & -1.36 & -1.31 \\
\hline & non-equivalent sites & $-1.37 /-0.86$ & $-1.75 /-0.82$ & $-1.34 /-1.48$ \\
\hline \multirow[t]{4}{*}{3} & line & -2.35 & -1.34 & - \\
\hline & off-set & -0.78 & -1.32 & - \\
\hline & triangle & -0.88 & -1.62 & -1.75 \\
\hline & 3D triangle & -3.86 & -2.46 & -2.25 \\
\hline \multirow[t]{4}{*}{4} & line & -1.60 & -1.52 & - \\
\hline & rhombus & -5.48 & -2.79 & -0.33 \\
\hline & 3D rectangle & -0.89 & -1.95 & -1.65 \\
\hline & tetrahedral & -5.37 & -2.75 & -2.41 \\
\hline
\end{tabular}




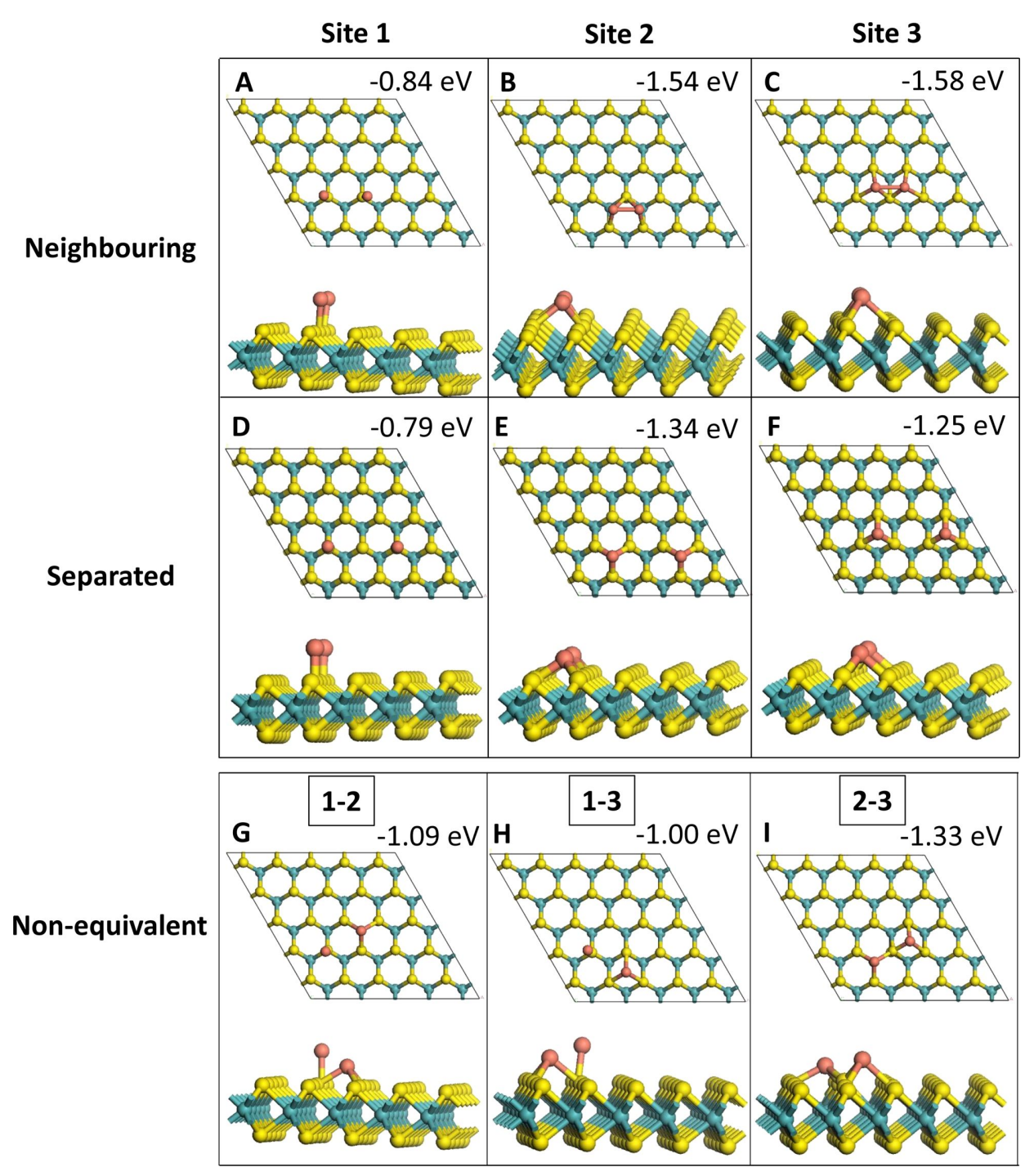

Figure 2: Adsorption configurations with two $\mathrm{Cu}$ adatoms. (A) through (F) show adatoms at equivalent sites, while $(\mathrm{G})$, $(\mathrm{H})$ and $(\mathrm{I})$ show combinations of two atoms adsorbed at different sites on the $\mathrm{MoS}_{2} \mathrm{ML}$.

$0.3 \mathrm{eV}$ to adsorb as $\mathrm{Cu}_{2}$ compared to separated adatom adsorption. This is also reflected in the addition energy for $\mathrm{Cu}$ to $\mathrm{Cu}_{2}$, as this is slightly more negative than both the binding energy per atom for this configuration as well as the binding energy of a single atom at each site.

Out of the non-equivalent $\mathrm{Cu}$ adatom adsorption modes, $\mathrm{Cu}_{2}$ as a combination of a $\mathrm{Cu}$ adatom at site $\mathbf{2}$ and one at site $\mathbf{3}$ was most favourable, because sites $\mathbf{2}$ and $\mathbf{3}$ are both more favourable than a $\mathrm{Cu}$ adatom at site $\mathbf{1}$. The addition energies were computed for addition of an atom at both sites, with a $\mathrm{Cu}$ atom already at the other site. With an atom adsorbed at site 1, adding a second atom at sites 2 or 3 gives an energy gain of -1.37 and $-1.75 \mathrm{eV}$, respectively, while adding an atom at site $\mathbf{1}$ gives an addition energy of $-0.86 \mathrm{eV}$ if the first atom is at site $\mathbf{2}$ and $-0.82 \mathrm{eV}$ if the adatom is at site $\mathbf{3}$. Thus, the more favourable addition energies are observed when adding an atom to the more favourable adsorption sites. Overall, adsorbing $\mathrm{Cu}$ at equivalent sites instead of non-equivalent sites yields a larger increase in binding energy per atom, except for the less stable site $\mathbf{1}$, where the combination with a more favourable adsorption site causes an increase in binding energy per atom.

Four different configurations were relaxed for the adsorption of three adatoms. Of these, three configurations are $2 \mathrm{D}$ and one is a $3 \mathrm{D}$ configuration in which two $\mathrm{Cu}$ atoms bind to $\mathrm{MoS}_{2}$. The computed binding energies show that the $3 \mathrm{D}$ configuration is the most stable of the four (see Table 1). Depending on the 


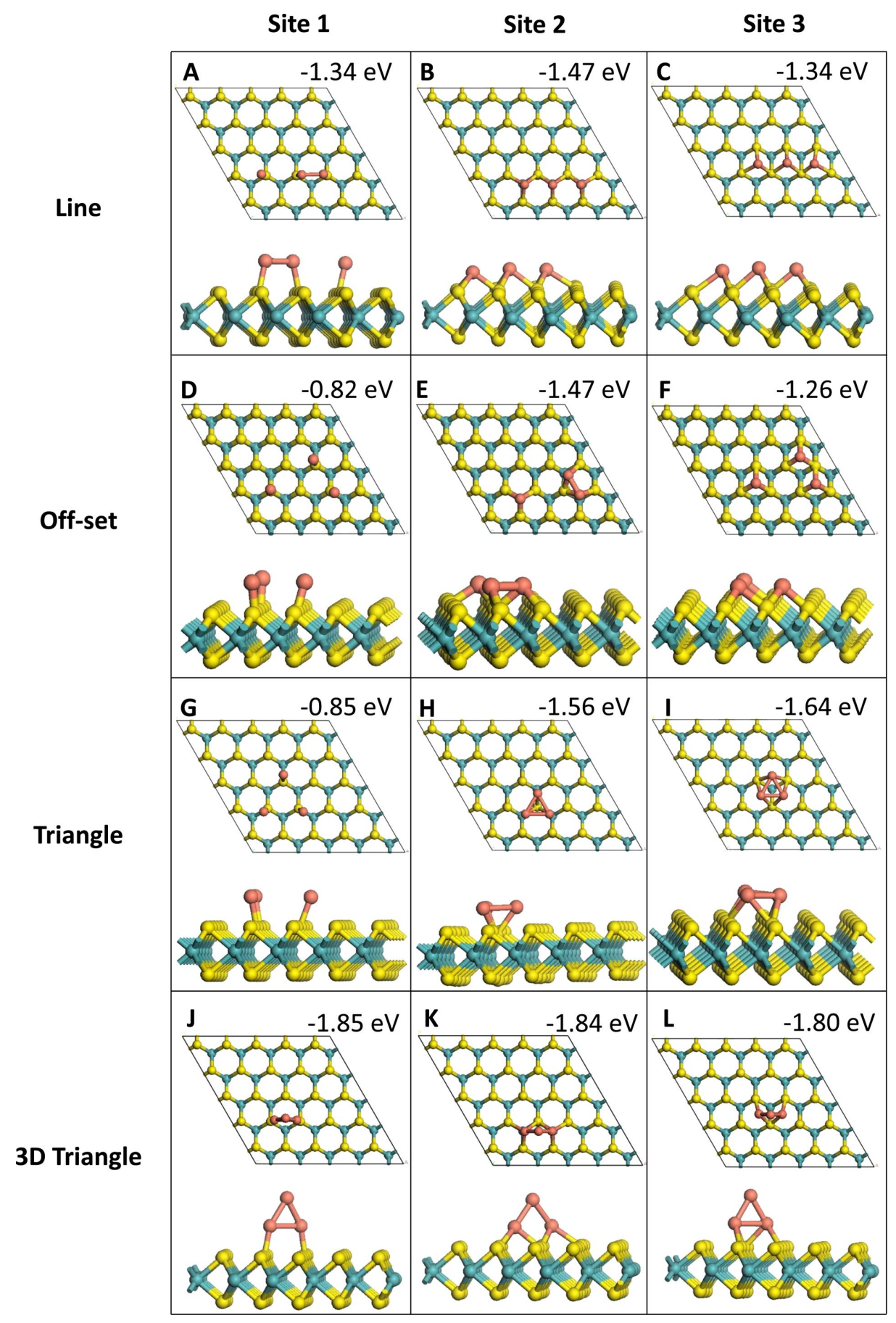

Figure 3: Relaxed structures after adsorption of $\mathrm{Cu}_{3}$ structures.

exact adsorption site and adsorption configuration, the $3 \mathrm{D} \mathrm{Cu}_{3}$ adsorption structure is more stable by 0.16 to $1.03 \mathrm{eV}$, compared to the various $2 \mathrm{D}$ structures. While site $\mathbf{1}$ continued to be less favourable than sites $\mathbf{2}$ and $\mathbf{3}$ for the 2D configurations, for the $3 \mathrm{D}$ adsorption mode this difference disappears, with similar binding energies for all sites, suggesting that once $3 \mathrm{D}$ clusters begin to form on $\mathrm{MoS}_{2}$ the binding energy is not influenced by the adsorption site. It is of note that the atoms remain at the site where they were originally adsorbed throughout relaxation. This is also apparent from the computed addition energies. The addition of an atom to $\mathrm{Cu}_{2}$ to form a $3 \mathrm{D} \mathrm{Cu}_{3}$ cluster is very favourable, with computed addition energies lying between 
Site 1

Site 2

Site 3

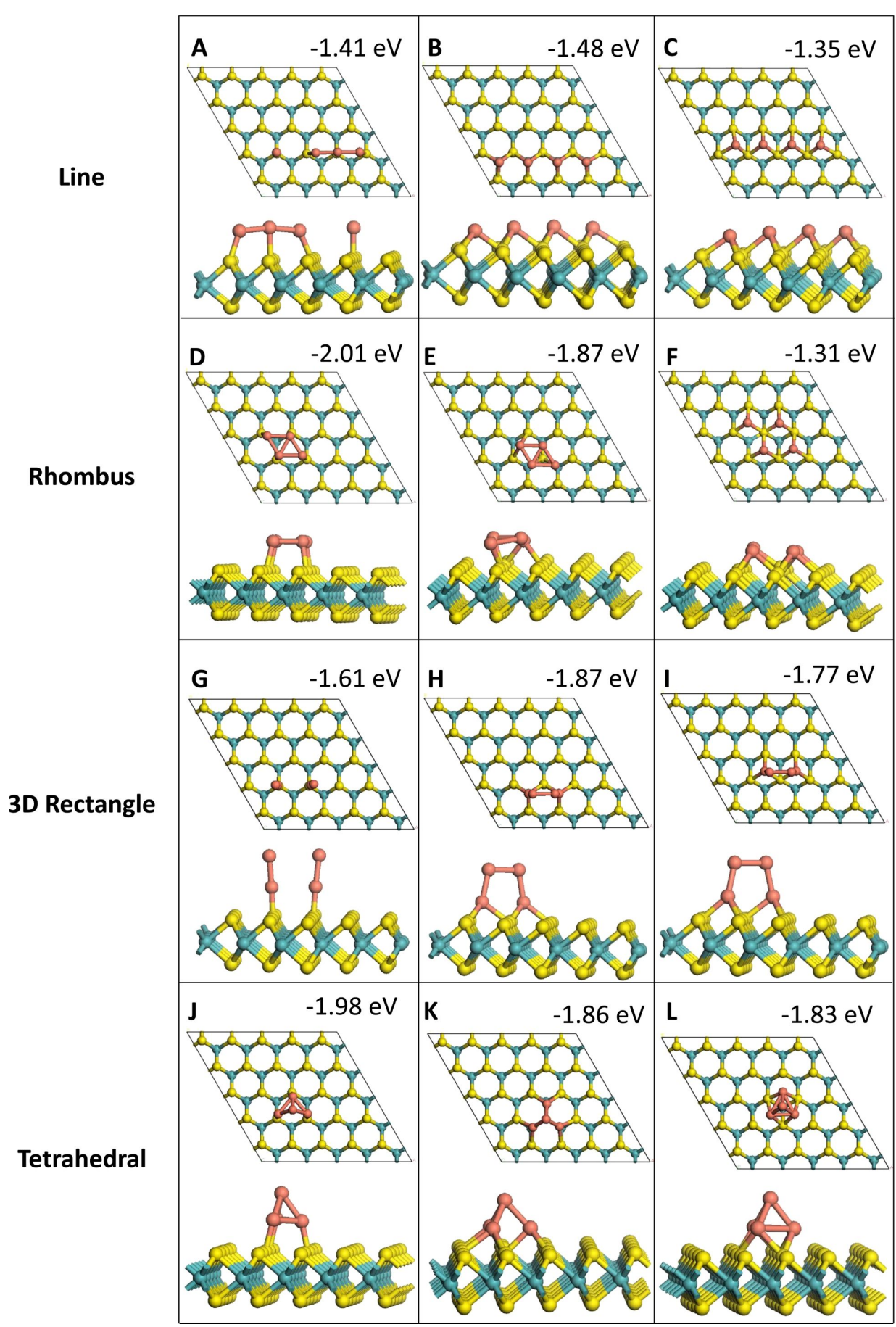

Figure 4: Relaxed structures after adsorption of $\mathrm{Cu}_{4}$ structures.

-2.25 and $-3.86 \mathrm{eV}$. The addition energy of $-3.86 \mathrm{eV}$ for site $\mathbf{1}$ reflects that this configuration is much more stable than any other three-atom configuration at site $\mathbf{1}$.

Finally, for the adsorption of four $\mathrm{Cu}$ atoms, four configurations were examined. Two configurations are flat (2D) and two configurations are 3D nanoclusters. For the flat adsorption structures, the four $\mathrm{Cu}$ atoms are adsorbed in a linear configuration, with $\mathrm{Cu}-\mathrm{Cu}$ distances of around $3.2 \AA$, depending on the adsorption site, or in a 4 -membered flat structure. In the $3 \mathrm{D}$ clusters, one configuration is a rhombus with two $\mathrm{Cu}$ atoms bound to $\mathrm{MoS}_{2}$ and the other $3 \mathrm{D}$ configuration is a tetrahedron 
with three atoms bound to $\mathrm{MoS}_{2}$ and an apex atom bound to the triangular base. Interestingly, for the 2D structures, binding of $\mathrm{Cu}$ atoms at site $\mathbf{1}$ becomes more favourable than binding of $\mathrm{Cu}$ atoms at site $\mathbf{3}$. As for the $\mathrm{Cu}_{3}$ structures, the atoms remain at their original adsorption site throughout the relaxation for all $\mathrm{Cu}_{4}$ structures. For the linear $\mathrm{Cu}_{4}$ configuration the binding energy at site $\mathbf{1}$ is only $0.06 \mathrm{eV}$ per $\mathrm{Cu}$ more negative than at site $\mathbf{3}$ and $0.07 \mathrm{eV}$ less negative than at site 2, indicating little difference in stability. We see that this is the weakest adsorption configuration of $\mathrm{Cu}_{4}$ at site $\mathbf{1}$. This is presumably a result of fewer $\mathrm{Cu}-\mathrm{Cu}$ bonds, as there is little variation in the $\mathrm{Cu}-\mathrm{Cu}$ bond lengths, which range from 2.24 to $2.41 \AA$ for structures at site 1 . However for the $2 \mathrm{D}$ rhombus adsorption configuration, site $\mathbf{1}$ is the most favourable site, with a binding energy that is $0.14 \mathrm{eV}$ more negative than that at site 2 and $0.70 \mathrm{eV}$ more negative than the binding energy at site $\mathbf{3}$. This is likely due to the $\mathrm{Cu}-\mathrm{Cu}$ interactions, which are in fact absent when adsorbing the rhombus structure at site $\mathbf{3}$, the weakest overall $\mathrm{Cu}_{4}$ adsorption configuration, due to long $\mathrm{Cu}-\mathrm{Cu}$ distances of 3.0 to $3.5 \AA$.

The rhombus configuration of $\mathrm{Cu}_{4}$ at site $\mathbf{1}$ has a computed addition energy of $-5.48 \mathrm{eV}$ relative to $\mathrm{Cu}_{3}$, which is the most favourable addition energy calculated, while the addition energy for the tetrahedral configuration at site $\mathbf{1}$ is similar with a value of $-5.37 \mathrm{eV}$. This indicates that $\mathrm{Cu}$ prefers this $\mathrm{Cu}_{4}$ structure with $\mathrm{Cu}-\mathrm{Cu}$ interactions compared to the corresponding $\mathrm{Cu}_{3}$ structure at site $\mathbf{1}$, which has no $\mathrm{Cu}-\mathrm{Cu}$ interactions. Site $\mathbf{2}$ has favourable addition energies for all four configurations. By contrast, site $\mathbf{3}$ has a much less favourable addition energy of only $-0.33 \mathrm{eV}$ for the rhombus configuration. For both 3D configurations, all three sites have very similar adsorption energies, further indicating the lack of influence of the adsorption site on the stability, with an energy difference between the 3D structures of around $0.1 \mathrm{eV}$. The addition energies for the tetrahedral configuration are much larger than those for the upright $3 \mathrm{D}$ adsorption configuration, with a difference of about $0.8 \mathrm{eV}$ for sites $\mathbf{2}$ and $\mathbf{3}$ and a difference of $4.48 \mathrm{eV}$ for site 1 . The $3 \mathrm{D}$ structures are more favourable than the $2 \mathrm{D}$ structures at site $\mathbf{3}$. However for sites $\mathbf{1}$ and $\mathbf{2}$, the rhombus configuration has a binding energy that is approximately the same as that of the tetrahedron. The instability of the rhombus at site $\mathbf{3}$ compared to the same configuration at sites $\mathbf{1}$ and $\mathbf{2}$ is likely due to the lack of $\mathrm{Cu}-\mathrm{Cu}$ bonds, which are present in structures at sites $\mathbf{1}$ and $\mathbf{2}$ but not at site $\mathbf{3}$ (see Figure 4F).

In general, the binding energy relative to free $\mathrm{Cu}_{n}$ clusters (Equation 2) shows the same trends as the binding energies per $\mathrm{Cu}$ atom from Equation 1. The off-set and triangle configurations for $\mathrm{Cu}_{3}$ at site $\mathbf{1}$ (as shown in Figure 3D,G) resulted in a positive binding energy when calculated with Equation 2, indi- cating that they are unstable. However, this is most likely due to the most favourable gas phase three-atom cluster having a different structure from that taken upon adsorption on the $\mathrm{MoS}_{2}$ ML. When calculating the stability using adsorbed $\mathrm{Cu}_{3}$ clusters, the structures were found to have relatively low binding energies of -0.82 and $-0.85 \mathrm{eV}$.

It is of note, that even though for single-atom adsorption, site $\mathbf{1}$ is the least favourable adsorption site, the most favourable binding energies are found for the rhombus and tetrahedral $\mathrm{Cu}_{4}$ configuration at site $\mathbf{1}$. These also had the most favourable addition energies, reflecting the large increase in stability of configurations at site $\mathbf{1}$ as subsequent $\mathrm{Cu}$ atoms are added. Overall, the binding energy per copper atom increases as more atoms are added, which is most likely due to the formation of $\mathrm{Cu}-\mathrm{Cu}$ bonds and more $\mathrm{Cu}$-surface bonds. The addition of $\mathrm{Cu}$ atoms also becomes more favourable, with the exception of the rhombus configuration of $\mathrm{Cu}_{4}$ at site 3 .

This analysis indicates that the relative stability of an adsorption configuration of a $\mathrm{Cu}_{n}$ species appears to be generally determined by the presence or absence of $\mathrm{Cu}-\mathrm{Cu}$ bonding. Those configurations with a larger number of $\mathrm{Cu}-\mathrm{Cu}$ bonds tend to have a more favourable binding energy. This becomes particularly clear for $\mathrm{Cu}_{4}$, where all structures other than the 3D tetrahedron are less favourable at site $\mathbf{3}$ than at sites $\mathbf{1}$ and $\mathbf{2}$. The distance from site $\mathbf{3}$ to another equivalent site is longest at approximately $3.2 \AA$, which then results in very long $\mathrm{Cu}-\mathrm{Cu}$ bonds, or in the case of $\mathrm{Cu}_{4}$ line and rhombus structures, no $\mathrm{Cu}-\mathrm{Cu}$ bonds.

$\mathrm{Cu}-\mathrm{S}$ distances also vary with adsorption site and are found to be shortest for $\mathrm{Cu}$ atom adsorption at site $\mathbf{1}$, with $\mathrm{Cu}-\mathrm{S}$ distances in the range of 2.16 to $2.31 \AA$. This is due to the $\mathrm{Cu}$ atom being adsorbed directly atop the $\mathrm{S}$ atom. In comparison, $\mathrm{Cu}-\mathrm{S}$ bond lengths are somewhat longer at the other sites, ranging from 2.23 to $2.54 \AA$ at site $\mathbf{2}$ and 2.26 to $2.58 \AA$ at site $\mathbf{3}$. Overall, the bond lengths appear to be determined by the adsorption site and do not have a strong effect on the strength of adsorption.

Bader charge analyses of $\mathrm{Cu}$ atoms and adjacent Mo and $\mathrm{S}$ atoms are shown in Table 4, Table 5 and Table 6. It shows that $\mathrm{Cu}$ atoms that bind directly with multiple sulfur atoms on the $\mathrm{MoS}_{2}$ layer, for example at sites $\mathbf{2}$ and $\mathbf{3}$, are clearly oxidised, with computed Bader charges of 10.6 electrons (the number of valance electrons in $\mathrm{Cu}$ is 11). In contrast, those $\mathrm{Cu}$ atoms that bind to a single sulfur atom, e.g., site $\mathbf{1}$, are less oxidised with a computed Bader charge of 10.8 electrons. $\mathrm{Cu}$ atoms that do not bind to the surface are metallic, with computed Bader charges of 11.0 to 11.1 electrons. There are no significant changes in the 
computed Bader charges of Mo and S atoms in the monolayer, which are ca. 4.9 and 6.5 electrons, respectively. Analysis of the charge density difference after $\mathrm{Cu}_{n}$ adsorption, confirms the observations made from the Bader analysis. Charge density is localised mainly at the adsorbed $\mathrm{Cu}$ atoms, with less charge density at those $\mathrm{Cu}$ atoms that are not bound to the surface. Some charge density is also observed in the surface $\mathrm{S}$ atoms interacting with $\mathrm{Cu}$ atoms, as well as those Mo atoms that are bound to the interacting S atoms. Figure S5A-G of Supporting Information File 1 shows the charge density difference of the most favourable $\mathrm{Cu}_{n}$ adsorption configurations.

\begin{tabular}{|c|c|c|c|}
\hline site & $\begin{array}{l}\text { adsorption } \\
\text { configuration }\end{array}$ & $\begin{array}{l}Q(\mathrm{Cu} \text { 1) } \\
\text { [electrons] }\end{array}$ & $\begin{array}{l}Q(\mathrm{Cu} 2) \\
\text { [electrons] }\end{array}$ \\
\hline 1 & single atom & 10.81 & - \\
\hline 2 & single atom & 10.62 & - \\
\hline 3 & single atom & 10.62 & - \\
\hline 1 & neighbouring & 10.81 & 10.81 \\
\hline 2 & neighbouring & 10.73 & 10.74 \\
\hline 3 & neighbouring & 10.83 & 10.84 \\
\hline 1 & separated & 10.85 & 10.86 \\
\hline 2 & separated & 10.62 & 10.61 \\
\hline 3 & separated & 10.62 & 10.60 \\
\hline $1-2$ & non-equivalent & 10.81 & 10.64 \\
\hline $1-3$ & non-equivalent & 10.82 & 10.62 \\
\hline $2-3$ & non-equivalent & 10.49 & 10.68 \\
\hline
\end{tabular}

Similarly, the bond lengths between Mo and S atoms in the monolayer do not vary significantly from those in the bare $\mathrm{MoS}_{2}$ monolayer after adsorption of $\mathrm{Cu}$ atoms. $\mathrm{Cu}-\mathrm{S}$ bonds can vary from the value in CuS bulk material (2.31 $\AA$ [41]) by up to $+0.27 \AA$, in the case of adsorption at site 3 , in particular the $\mathrm{Cu}_{4}$ line configuration, or by $-0.15 \AA$, in the case of most of the adsorption configurations at site 1 . Mo-S distances are found to be within $+0.09 \AA$ and $-0.05 \AA$ of the Mo-S distance in the bare ML (2.41 $\AA$ ). Thus, no significant structural distortion occurs in $\mathrm{MoS}_{2}$ after $\mathrm{Cu}$ adsorption. We conclude, that there is no clear correlation between the $\mathrm{Cu}-\mathrm{S}$ or $\mathrm{Mo}-\mathrm{S}$ distances and the favourability of a binding site.

Analysis of the density of states (DOS) (see Figure 5 for the most favourable adsorption structures for each $\mathrm{Cu}_{n}$ structure) shows the emergence of mid-gap states as $\mathrm{Cu}$ atoms are added to the monolayer. These states arise from the partial oxidation of $\mathrm{Cu}$ atoms to produce $\mathrm{Cu}^{+}$cations and include contributions
Table 5: Computed Bader charge $(Q)$ at each $\mathrm{Cu}$ atom for different adsorption configurations of three $\mathrm{Cu}$ atoms. In 3D structures, $\mathrm{Cu}_{-} 1$ and $\mathrm{Cu}_{2} 2$ are interacting with the monolayer, while $\mathrm{Cu}_{-} 3$ is at the apex of the triangle.

\begin{tabular}{lllll} 
site & configuration & $Q\left(\mathrm{Cu}_{-} 1\right)$ & $Q\left(\mathrm{Cu} \_2\right)$ & $Q\left(\mathrm{Cu} \_3\right)$ \\
\hline 1 & line & 10.82 & 10.87 & 10.85 \\
2 & line & 10.65 & 10.77 & 10.64 \\
3 & line & & & \\
& & & & \\
1 & off-set & 10.84 & 10.81 & 10.82 \\
2 & off-set & 10.63 & 10.73 & 10.74 \\
3 & off-set & & & \\
& & & & \\
1 & triangle & 10.81 & 10.80 & 10.81 \\
2 & triangle & 10.76 & 10.75 & 10.74 \\
3 & triangle & 10.77 & 10.75 & 10.76 \\
& & & & \\
1 & 3D triangle & 10.76 & 10.76 & 11.00 \\
2 & 3D triangle & 10.67 & 10.67 & 11.07 \\
3 & 3D triangle & 10.72 & 10.73 & 11.02 \\
& & & & \\
& & & &
\end{tabular}

Table 6: Computed Bader charge $(Q)$ at each $\mathrm{Cu}$ atom for different adsorption configurations with four $\mathrm{Cu}$ atoms. For the $3 \mathrm{D}$ rectangle configurations, $\mathrm{Cu}$ 1 1 and $\mathrm{Cu} 2$ are interacting with the monolayer and $\mathrm{Cu} 3$ and $\mathrm{Cu} \_4$ are adsorbed atop of $\mathrm{Cu} 1$ and $\mathrm{Cu}$ 2. For the tetrahedron, $\mathrm{Cu} 44$ is at the apex, while $\mathrm{Cu}_{-} 1, \mathrm{Cu}_{-} 2$ and $\mathrm{Cu}_{-} 3$ are all interacting with the $\mathrm{MoS}_{2}$ monolayer.

\begin{tabular}{llllll} 
site & configuration & $Q\left(\mathrm{Cu}_{-} 1\right)$ & $Q\left(\mathrm{Cu} \_\right)$ & $Q(\mathrm{Cu} 3)$ & $Q(\mathrm{Cu} 4)$ \\
\hline 1 & line & 10.78 & 10.84 & 10.97 & 10.84 \\
2 & line & 10.62 & 10.77 & 10.77 & 10.61 \\
3 & line & 10.61 & 10.78 & 10.79 & 10.62 \\
& & & & & \\
1 & rhombus & 10.90 & 10.83 & 10.92 & 10.80 \\
2 & rhombus & 10.84 & 10.85 & 10.80 & 10.83 \\
3 & rhombus & 10.61 & 10.78 & 10.79 & 10.62 \\
& & & & & \\
1 & 3D rectangle & 10.80 & 10.80 & 11.11 & 11.11 \\
2 & 3D rectangle & 10.70 & 10.71 & 11.05 & 11.05 \\
3 & 3D rectangle & 10.71 & 10.71 & 11.03 & 11.04 \\
& & & & & \\
1 & tetrahedron & 10.87 & 10.75 & 10.87 & 11.00 \\
2 & tetrahedron & 10.68 & 10.67 & 10.69 & 11.07 \\
3 & tetrahedron & 10.72 & 10.71 & 10.71 & 11.00
\end{tabular}

from all three elements. Exceptions to this are the 3D triangle configurations at adsorption sites $\mathbf{1}$ and $\mathbf{3}$, where there is no mid-gap state with all of the $\mathrm{Cu}$ contributions at the Fermi level. Density of states plots for all $\mathrm{Cu}_{n}$ structures can be found in Supporting Information File 1, Figures S1-S3. 


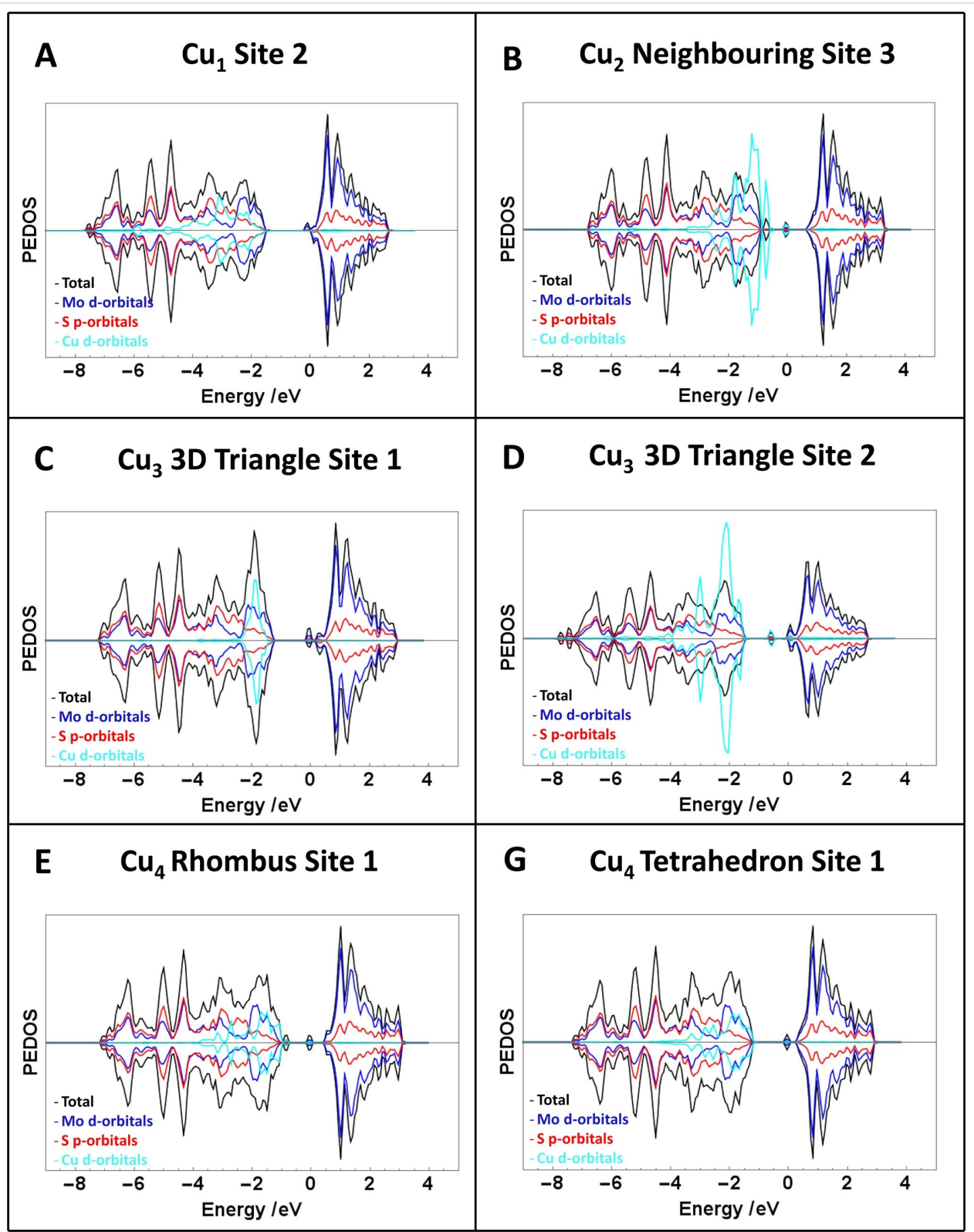

Figure 5: DOS plots of most favourable adsorption configuration for each $\mathrm{Cu}_{n}$ structure on $\mathrm{MoS}_{2}$. The contribution of the Cu d orbitals has been increased by a factor of five for the ease of comparison and zero on the "energy" scale is the Fermi level.

\section{Cu adsorption on $\mathrm{MoS}_{2}$ with one S vacancy}

$\mathrm{S}$ vacancies can form in $\mathrm{MoS}_{2}$ monolayers with relative ease [2]. Le et al. showed that these vacancies become more stable when a row of vacancies is present in the monolayer. For the purpose of this study we limit ourselves to a single vacancy in the monolayer, giving us a first insight of how $\mathrm{Cu}$ adsorption is affected by the presence of a sulfur vacancy. Single $\mathrm{Cu}$ atoms and $\mathrm{Cu}_{4}$ nanoclusters were adsorbed on the defective $\mathrm{MoS}_{2}$ surface with a single sulfur vacancy. While all single-atom adsorption configurations that we investigated are stable, only five of the twelve $\mathrm{Cu}_{4}$ nanocluster structures were stable upon relaxa- tion. For those adsorption structures that were not stable we generally find $\mathrm{Cu}$ atoms repelled from the surface and an endothermic adsorption energy. An example is shown in Supporting Information File 1, Figure S6 where a $\mathrm{Cu}$ atom is repelled from the defective monolayer during the geometry relaxation of $\mathrm{a} \mathrm{Cu}_{4}$ rhombus structure adsorbed at site $\mathbf{1}$ and near the sulfur vacancy.

The binding energies of $\mathrm{Cu}$ and $\mathrm{Cu}_{4}$, using Equations 1 and 2, are presented in Table 7 and the stable adsorption geometries are shown in Figure 6. Comparing with the stoichiometric $\mathrm{MoS}_{2}$ monolayer, Figure 6, all binding energies are more 
Table 7: Computed binding energies per $\mathrm{Cu}$ atom of one and four $\mathrm{Cu}$ atoms and binding energies of the $\mathrm{Cu}_{4}$ nanocluster relative to a free $\mathrm{Cu}_{4}$ nanocluster on $\mathrm{MoS}_{2}$ with a sulfur vacancy for the adsorption of a single $\mathrm{Cu}$ atom and the $\mathrm{Cu}_{4}$ nanocluster.

\begin{tabular}{|c|c|c|c|c|c|c|c|}
\hline \multirow{2}{*}{$\begin{array}{l}\text { number of } \mathrm{Cu} \\
\text { atoms }\end{array}$} & \multirow[t]{2}{*}{ configuration } & \multicolumn{3}{|c|}{$E_{\text {bind }} /$ atom $[\mathrm{eV}]$} & \multicolumn{3}{|c|}{$E_{\text {bind }}[\mathrm{eV}]$} \\
\hline & & site 1 & site 2 & site 3 & site 1 & site 2 & site 3 \\
\hline 1 & - & -2.76 & -1.35 & -1.24 & -2.76 & -1.35 & -1.24 \\
\hline \multirow[t]{3}{*}{4} & line & -1.75 & -1.83 & - & -3.01 & -3.30 & - \\
\hline & rhombus & - & -2.26 & - & - & -5.02 & - \\
\hline & tetrahedral & - & -2.05 & -1.93 & - & -4.20 & -3.31 \\
\hline
\end{tabular}

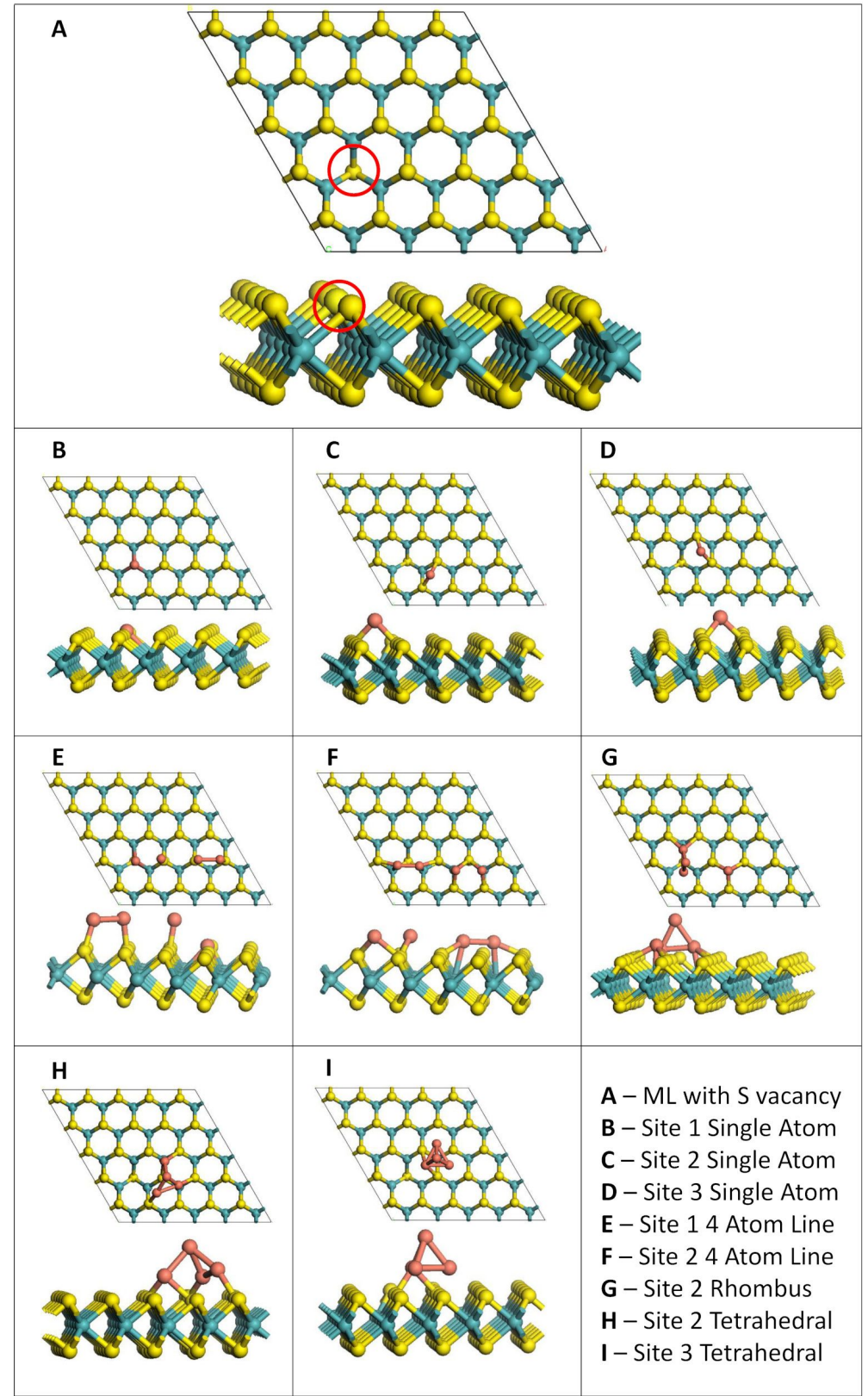

Figure 6: Bare $\mathrm{MoS}_{2} \mathrm{ML}$ with S vacancy (highlighted in red) and adsorption structures for $\mathrm{Cu}_{1}$ and $\mathrm{Cu}_{4}$ adsorbed on $\mathrm{MoS}_{2}$ with one sulfur vacancy. 
favourable for adsorption on the defective monolayer. The largest increase in the computed binding energy is $1.95 \mathrm{eV}$, and this was observed for the single $\mathrm{Cu}$ atom adsorption initially at site 1. Upon relaxation, the adsorbed $\mathrm{Cu}$ atom migrates into the vacancy site and replaces the missing $\mathrm{S}$ atom. This results in $\mathrm{Cu}-\mathrm{Mo}$ distances of 2.60 to $2.63 \AA$ and there are no bonds to the surrounding $\mathrm{S}$ atoms. In contrast, adsorption of the $\mathrm{Cu}$ atom at sites $\mathbf{2}$ and $\mathbf{3}$, away from the vacancy site, results in an increase in the binding energy of only 0.03 and $0.06 \mathrm{eV}$. Cu-S bonds are ca. $2.18 \AA$ for adsorption at sites $\mathbf{2}$ and $\mathbf{3}$, which is only slightly longer than the $\mathrm{Cu}-\mathrm{S}$ distance of $2.15 \AA$ for adsorption on the pristine surface. This indicates that the influence of a single sulfur vacancy in the monolayer is localised.

For the adsorption of the four-atom nanocluster, the largest increase in the computed binding energy is found for the initial flat rhombus configuration at site 2 . Upon relaxation, three of the four $\mathrm{Cu}$ atoms migrate towards the vacancy and rearrange to form a 3D triangle structure. The fourth atom remains at site $\mathbf{2}$, which is located away from the vacancy, as shown in Figure 6G. The change in the binding energy is $0.39 \mathrm{eV}$ compared to the $\mathrm{Cu}_{4}$ rhombus configuration at site 2 and $0.42 \mathrm{eV}$ compared to the $3 \mathrm{D}$ triangle at the same site, making this structure the most favourable of the four-atom configurations. $\mathrm{Cu}-\mathrm{S}$ distances are between 2.22 and $2.33 \AA$, while the $\mathrm{Cu}-\mathrm{Cu}$ distances are between $2.33 \AA$ and $2.35 \AA$. The $\mathrm{Cu}-\mathrm{S}$ bonds are shorter compared to the $3 \mathrm{D}$ triangle at site 2 on the pristine surface, which has $\mathrm{Cu}-\mathrm{S}$ distances between 2.31 and $2.46 \AA$, while the $\mathrm{Cu}-\mathrm{Cu}$ distances are of similar length, ranging between 2.35 and $2.36 \AA$. The shorter $\mathrm{Cu}-\mathrm{S}$ distances likely contribute to the more favourable binding energy. Similar to the stoichiometric monolayer, the stable tetrahedral configurations (at sites $\mathbf{2}$ and 3, Figure $6 \mathrm{H}, \mathrm{I}$ ) are similar in energy, with a difference in stability of only $0.12 \mathrm{eV}$. Cu-S distances are between 2.29 and $2.36 \AA$ and $\mathrm{Cu}-\mathrm{Cu}$ distances are between 2.40 and $2.50 \AA$. These are some of the longest distances observed on the defective ML. However, they are somewhat shorter than those on the pristine surface, where the maximum $\mathrm{Cu}-\mathrm{S}$ and $\mathrm{Cu}-\mathrm{Cu}$ distances are 2.59 and $2.73 \AA$, respectively. This difference should contribute to the enhanced binding at the defective $\mathrm{MoS}_{2} \mathrm{ML}$.

The adsorption of four $\mathrm{Cu}$ atoms in a linear fashion (Figure 6E,F) is stable at both sites $\mathbf{1}$ and $\mathbf{2}$ on the defective $\mathrm{ML}$, although these adsorption structures are not as favourable as the clustered structures, which is again due to the lack of $\mathrm{Cu}-\mathrm{Cu}$ interactions. At site $\mathbf{1}$, one of the four $\mathrm{Cu}$ atoms moves into the vacancy site, while two of four $\mathrm{Cu}$ atoms bind at the vacancy site for the site $\mathbf{2}$ configuration. These are the only two four-atom configurations where $\mathrm{Cu}-\mathrm{Mo}$ interactions were observed, with distances between 2.62 and $2.65 \AA$. The $\mathrm{Cu}-\mathrm{S}$ distances lie between 2.17 and $2.27 \AA$, while the $\mathrm{Cu}-\mathrm{Cu}$ distances are $2.28 \AA$ at site $\mathbf{1}$ and $2.29 \AA$ at site 2. Overall, the range of distances for $\mathrm{Cu}$ adsorption on the defective $\mathrm{MoS}_{2}$ monolayer is narrower compared to the range of distances on the pristine surface. $\mathrm{Cu}-\mathrm{Cu}$ distances are of similar lengths to those measured for structures on the pristine surface, and are slightly shorter than the distances in bulk copper. As for the pristine surface, there is no clear correlation between the geometry and the strength of binding.

The presence of a defect did not cause any notable geometry distortions in the monolayer. This is supported by Mo-S distances at the copper adsorption sites, which lie between 2.38 and $2.49 \AA$, which is close to the Mo-S distance of $2.42 \AA$ in bare $\mathrm{MoS}_{2}$. Some distortion was observed for the $3 \mathrm{D} \mathrm{Cu}$ clusters (see Figure 6F, G in particular), which is caused by the migration of one or more $\mathrm{Cu}$ atoms towards the vacancy site.

The computed Bader charges determined for the $\mathrm{Cu}$ atoms on the defective monolayer are shown in Table 8. The computed Bader charge at the $\mathrm{Cu}$ atom at site $\mathbf{1}$ indicates little oxidation of the $\mathrm{Cu}$ atom. This arises due to coordination of $\mathrm{Cu}$ to three Mo atoms so that oxidation of the $\mathrm{Cu}$ is not favourable. The other binding sites have computed Bader charges consistent with the oxidation of $\mathrm{Cu}^{0}$ to $\mathrm{Cu}^{+}$, which are similar to the Bader charges computed for $\mathrm{Cu}$ adsorption at the bare monolayer, as detailed in Table 4 and Table 6.

\begin{tabular}{|c|c|c|c|c|c|}
\hline site & configuration & $Q($ Cu_1 $)$ & $Q\left(\mathrm{Cu} \_2\right)$ & $Q(\mathrm{Cu}$ _3 $)$ & $Q\left(\mathrm{Cu} \_4\right)$ \\
\hline 1 & single atom & 10.87 & - & - & - \\
\hline 2 & single atom & 10.52 & - & - & - \\
\hline 3 & single atom & 10.49 & - & - & - \\
\hline 1 & line & 10.89 & 10.85 & 10.88 & 10.84 \\
\hline 2 & line & 10.81 & 10.83 & 10.66 & 10.63 \\
\hline 2 & rhombus & 11.08 & 10.76 & 10.84 & 10.48 \\
\hline 2 & tetrahedral & 10.71 & 10.65 & 10.66 & 11.05 \\
\hline 3 & tetrahedral & 10.64 & 10.65 & 10.66 & 10.99 \\
\hline
\end{tabular}

Comparing the different $\mathrm{Cu}_{4}$ adsorption structures, we find that in the two linear configurations the adsorbed $\mathrm{Cu}$ atoms are partially oxidised, with computed Bader charges of 10.84 to 10.89 electrons for the adsorption at site $\mathbf{1}$ and 10.63 to 10.83 electrons for the adsorption at site $\mathbf{2}$. In the case of adsorption at site 2 , the two atoms closest to the vacancy $\left(\mathrm{Cu}_{-} 1\right.$ and $\mathrm{Cu}_{-} 2$ in Table 8) are less oxidised than those further away. In the tetra- 
hedral/triangular structures, the computed Bader charges for the $\mathrm{Cu}$ atoms directly bound to the monolayer are consistent with an oxidation to $\mathrm{Cu}^{+}$, while the remaining $\mathrm{Cu}$ atoms that do not interact with the monolayer are metallic. We further note that atoms are only partially oxidised when they are bound at the vacancy, while oxidation to $\mathrm{Cu}^{+}$occurs for atoms further away from the vacancy. The same observations were also found for the pristine surface, indicating that the presence of the vacancy does not directly affect the charge transfer unless the $\mathrm{Cu}$ atom is adsorbed in or beside the vacancy site. Analysing the charge density difference for the two most favourable adsorption modes, shows that in contrast to the pristine surface the charge density is not limited to just adsorbed $\mathrm{Cu}$ atoms and the $\mathrm{S}$ and Mo atoms interacting directly with the $\mathrm{Cu}$ atoms. Instead, some charge density is delocalized to the $\mathrm{S}$ and Mo atoms neighbouring the S vacancy. Figure S5I and Figure S5H (Supporting Information File 1) show the charge density difference of the most favourable $\mathrm{Cu}_{n}$ adsorption configurations on defective $\mathrm{MoS}_{2}$.

Figure 7 shows the density of states for the three most favourable $\mathrm{Cu}$ adsorption configurations on defective $\mathrm{MoS}_{2}$. Density of states plots of all other adsorption configurations can be found in Supporting Information File 1, Figure S4. The general features of the DOS are similar to those of the pristine surface, in which mid-gap states originating from the presence of adsorbed copper can be seen for all configurations.

\section{Conclusion}

The adsorption of metal species on semiconducting supports such as $2 \mathrm{D}$ monolayers of $\mathrm{MoS}_{2}$ is a subject of significant interest in a range of applications, particularly in catalysis and, more recently, in semiconductor nanodevices where 2D materials can function as barrier materials to prevent copper diffusion into the underlying dielectric material. While there have been studies of single-atom adsorption at $\mathrm{MoS}_{2}[26,29]$ and the adsorption of larger nanoclusters of noble metals, [25] there is as yet no comprehensive study of the interactions of small subnanometer metal species with a $\mathrm{MoS}_{2} \mathrm{ML}$, which is useful to probe the fundamental metal- $\mathrm{MoS}_{2}$ interactions. In this study, we investigated the adsorption behaviour of small $\mathrm{Cu}_{n}$ nanoclusters $(n=1-4)$ through first-principles density functional theory.

We find that a single $\mathrm{Cu}$ atom prefers to adsorb above a Mo atom, compared to adsorption atop $\mathrm{S}$ or in the hollow site of the Mo-S hexagon. However, as $n$ increases, the effect of the adsorption site on the binding energy becomes less important, although the atoms remain at their original adsorption site throughout the relaxation. Interestingly, $\mathrm{Cu}_{4}$ clusters seem to prefer to adsorb with the $\mathrm{Cu}$ atoms atop the $\mathrm{S}$ atoms, even

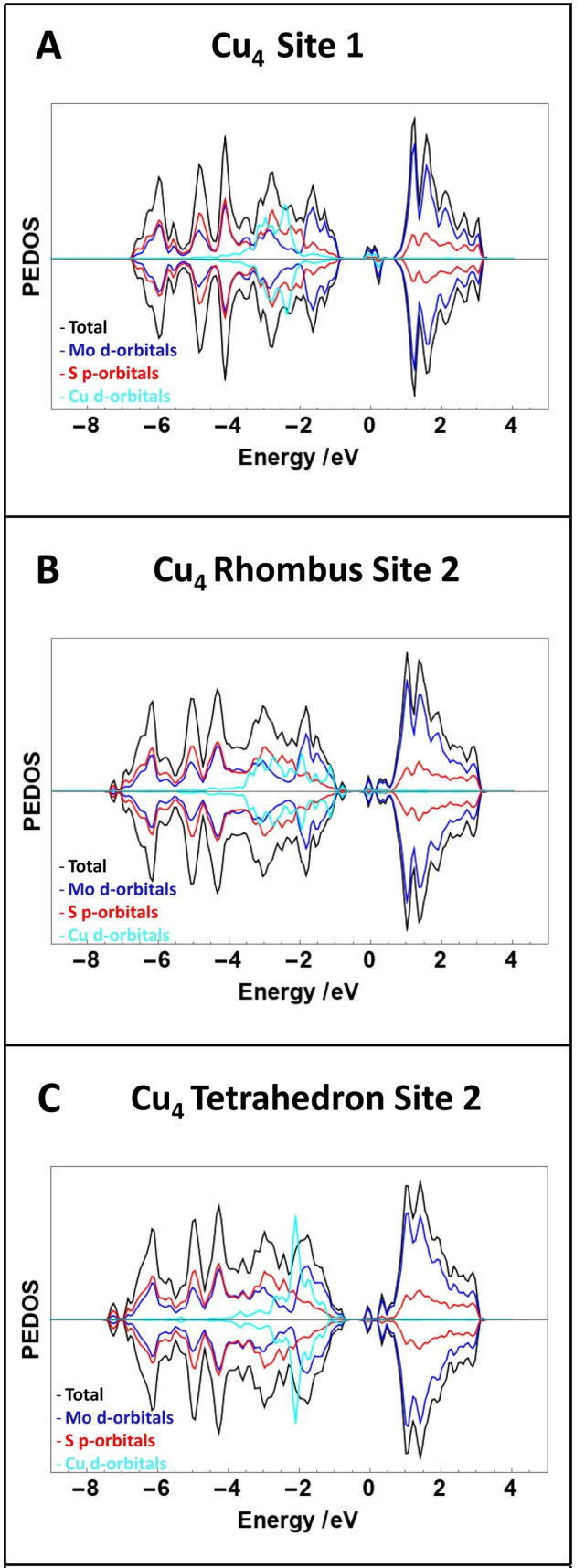

Figure 7: DOS plots of most favourable $\mathrm{Cu}_{1}$ and $\mathrm{Cu}_{4}$ adsorption structures on defective $\mathrm{MoS}_{2}$. The contribution of the $\mathrm{Cu} \mathrm{d}$ orbitals has been increased by a factor of five for the ease of comparison and zero on the "energy" scale is the Fermi level.

though this is the least favourable adsorption site for a single atom. This can be attributed to the shorter distance between $\mathrm{Cu}$ and $\mathrm{S}$, which facilitates the formation of more $\mathrm{Cu}-\mathrm{Cu}$ bonds.

Bader charge analysis shows that $\mathrm{Cu}$ atoms interacting with the $\mathrm{MoS}_{2} \mathrm{ML}$ are oxidised to $\mathrm{Cu}^{+}$, while the apex atoms in the 3D structures, which only interact with other $\mathrm{Cu}$ atoms, remain as 
metallic $\mathrm{Cu}^{0}$ species. Overall, the relative stability of a $\mathrm{Cu}_{n}$ adsorption structure is driven by the $\mathrm{Cu}-\mathrm{Cu}$ interactions, which are in turn promoted by the distance between adsorption sites. This leads to $3 \mathrm{D} \mathrm{Cu}$ structures having similar binding energies regardless of adsorption site. Further, there is no real preference between the $2 \mathrm{D} \mathrm{Cu}_{4}$ rhombus structure, which has the largest number of $\mathrm{Cu}-\mathrm{Cu}$ bonds of any of the $2 \mathrm{D}$ structures, and the two $3 \mathrm{D} \mathrm{Cu}_{4}$ structures studied.

Removing a single $\mathrm{S}$ atom from the $\mathrm{MoS}_{2}$ monolayer, which is highly favourable, enhances the binding of $\mathrm{Cu}$ nanoclusters to the $\mathrm{MoS}_{2}$ ML. The effect of the vacancy is found to be localised and charge transfer follows the same trend as on the pristine surface unless a $\mathrm{Cu}$ atom adsorbs in the vacancy site, which is a highly favourable process; in this case oxidation of the $\mathrm{Cu}$ atom is less pronounced.

Although there are many $\mathrm{Cu}_{4}$ adsorption structures that are stable on the pristine ML, they are no longer stable upon adsorption at the defective ML. There is a preference for $3 \mathrm{D}$ structures on the defective $\mathrm{MoS}_{2}$ ML. In future work, larger $\mathrm{Cu}_{n}$ structures will be required to explore if $\mathrm{Cu}$ grows as a $2 \mathrm{D}$ $\mathrm{Cu}$ film or prefers to form $3 \mathrm{D}$ clusters and how this can be tuned by the stoichiometry of the $\mathrm{MoS}_{2}$ ML.

\section{Supporting Information}

\section{Supporting Information File 1}

Additional computational data

[https://www.beilstein-journals.org/bjnano/content/ supplementary/2190-4286-11-30-S1.pdf]

\section{Acknowledgements}

We are grateful for access to Tyndall computing facilities supported by SFI and the Irish Centre for High End Computing (https://www.ichec.ie).

\section{Funding}

We acknowledge support for this work from the Science Foundation Ireland-NSF China Partnership Program, NITRALD Grant number: 17/NSFC/5279.

\section{ORCID ${ }^{\circledR}$ iDs}

Cara-Lena Nies - https://orcid.org/0000-0003-0959-2615 Michael Nolan - https://orcid.org/0000-0002-5224-8580

\section{Preprint}

A non-peer-reviewed version of this article has been previously published as a preprint https://doi.org/10.26434/chemrxiv.10118324.v1

\section{References}

1. Novoselov, K. S.; Jiang, D.; Schedin, F.; Booth, T. J.; Khotkevich, V. V.; Morozov, S. V.; Geim, A. K. Proc. Natl. Acad. Sci. U. S. A. 2005, 102, 10451-10453. doi:10.1073/pnas.0502848102

2. Le, D.; Rawal, T. B.; Rahman, T. S. J. Phys. Chem. C 2014, 118 , 5346-5351. doi:10.1021/jp411256g

3. Sharma, A.; Srivastava, A.; Husain, M.; Khan, M. S. J. Mater. Sci. 2018, 53, 9578-9588. doi:10.1007/s10853-018-2269-5

4. Choi, W.; Choudhary, N.; Han, G. H.; Park, J.; Akinwande, D.; Lee, Y. H. Mater. Today 2017, 20, 116-130. doi:10.1016/j.mattod.2016.10.002

5. O'Dwyer, C.; Walsh, L. A.; Gity, F.; Bhattacharjee, S.; Hurley, P. K. Electrochem. Soc. Interface 2018, 27 (4), 53-58. doi:10.1149/2.f06184if

6. Samad, A.; Shafique, A.; Shin, Y.-H. Nanotechnology 2017, 28, 175401. doi:10.1088/1361-6528/aa6536

7. Keong Koh, E. W.; Chiu, C. H.; Lim, Y. K.; Zhang, Y.-W.; Pan, H. Int. J. Hydrogen Energy 2012, 37, 14323-14328. doi:10.1016/j.ijhydene.2012.07.069

8. Zhang, Y.-H.; Chen, J.-L.; Yue, L.-J.; Zhang, H.-L.; Li, F. Comput. Theor. Chem. 2017, 1104, 12-17. doi:10.1016/j.comptc.2017.01.026

9. Ding, Y.; Wang, Y.; Ni, J.; Shi, L.; Shi, S.; Tang, W. Phys. B (Amsterdam, Neth.) 2011, 406, 2254-2260. doi:10.1016/j.physb.2011.03.044

10. Zahid, F.; Liu, L.; Zhu, Y.; Wang, J.; Guo, H. AIP Adv. 2013, 3, 052111. doi:10.1063/1.4804936

11. Nerl, H. C.; Pokle, A.; Jones, L.; Müller-Caspary, K.; van den Bos, K. H. W.; Downing, C.; McCarthy, E. K.; Gauquelin, N.; Ramasse, Q. M.; Lobato, I.; Daly, D.; Idrobo, J. C.; Van Aert, S.; Van Tendeloo, G.; Sanvito, S.; Coleman, J. N.; Cucinotta, C. S.; Nicolosi, V. Adv. Funct. Mater. 2019, 29, 1903120. doi:10.1002/adfm.201903120

12. Lo, C.-L.; Smithe, K. K. H.; Mehta, R.; Chugh, S.; Pop, E.; Chen, Z. Atomically thin diffusion barriers for ultra-scaled $\mathrm{Cu}$ interconnects implemented by 2D materials. 2017 IEEE International Reliability Physics Symposium (IRPS); 2017; MR-4.1-MR-4.4. doi:10.1109/irps.2017.7936379

13. Smithe, K. K. H.; Zhu, Z.; Bailey, C. S.; Pop, E.; Yoon, A. Investigation of monolayer MX2 as sub-nanometer copper diffusion barriers. 2018 IEEE International Reliability Physics Symposium (IRPS); 2018; P-PI.1-1-P-PI.1-4. doi:10.1109/irps.2018.8353681

14. Lo, C.-L.; Catalano, M.; Smithe, K. K. H.; Wang, L.; Zhang, S.; Pop, E.; Kim, M. J.; Chen, Z. npj 2D Mater. Appl. 2017, 1, 42. doi:10.1038/s41699-017-0044-0

15. Lo, C.-L.; Zhang, K.; Smith, R. S.; Shah, K.; Robinson, J. A.; Chen, Z. IEEE Electron Device Lett. 2018, 39, 873-876. doi:10.1109/led.2018.2827061

16. Shi, Y.; Li, H.; Li, L.-J. Chem. Soc. Rev. 2015, 44, 2744-2756. doi:10.1039/c4cs00256c

17. Olofinjana, B.; Egharevba, G.; Taleatu, B.; Akinwunmi, O.; Ajayi, E. O. J. Mod. Phys. 2011, 2, 341-349. doi:10.4236/jmp.2011.25042

18. Pyeon, J. J.; Kim, S. H.; Jeong, D. S.; Baek, S.-H.; Kang, C.-Y.; Kim, J.-S.; Kim, S. K. Nanoscale 2016, 8, 10792-10798. doi:10.1039/c6nr01346e

19. Mattinen, M.; Hatanpää, T.; Sarnet, T.; Mizohata, K.; Meinander, K.; King, P. J.; Khriachtchev, L.; Räisänen, J.; Ritala, M.; Leskelä, M. Adv. Mater. Interfaces 2017, 4, 1700123. doi:10.1002/admi.201700123 
20. Mak, K. F.; Lee, C.; Hone, J.; Shan, J.; Heinz, T. F. Phys. Rev. Lett. 2010, 105, 136805. doi:10.1103/physrevlett.105.136805

21. Addou, R.; Colombo, L.; Wallace, R. M. ACS Appl. Mater. Interfaces 2015, 7, 11921-11929. doi:10.1021/acsami.5b01778

22. Egami, Y.; Tsukamoto, S.; Ono, T. Quantum Matter 2017, 6, 4-17. doi:10.1166/qm.2017.1390

23. Ataca, C.; Şahin, H.; Ciraci, S. J. Phys. Chem. C 2012, 116, 8983-8999. doi:10.1021/jp212558p

24. Salehi, H.; Moaddeli, M.; Amiri, P. Surf. Sci. 2016, 647, 96-102. doi:10.1016/j.susc.2015.12.028

25. Rawal, T. B.; Le, D.; Rahman, T. S. J. Phys. Chem. C 2017, 121, 7282-7293. doi:10.1021/acs.jpcc.7b00036

26. Wang, Y.; Wang, B.; Huang, R.; Gao, B.; Kong, F.; Zhang, Q. Phys. E (Amsterdam, Neth.) 2014, 63, 276-282. doi:10.1016/j.physe.2014.06.017

27. Ma, D.; Ju, W.; Li, T.; Zhang, X.; He, C.; Ma, B.; Tang, Y.; Lu, Z.; Yang, Z. Appl. Surf. Sci. 2016, 364, 181-189. doi:10.1016/j.apsusc.2015.12.142

28. Zhao, R.; Lo, C.-L.; Zhang, F.; Ghosh, R. K.; Knobloch, T.; Terrones, M.; Chen, Z.; Robinson, J. Adv. Mater. Interfaces 2019, 6, 1901055. doi:10.1002/admi.201901055

29. Li, X. D.; Fang, Y. M.; Wu, S. Q.; Zhu, Z. Z. AIP Adv. 2015, 5, 057143. doi:10.1063/1.4921564

30. Ersan, F.; Gökoğlu, G.; Aktürk, E. J. Phys. Chem. C 2015, 119, 28648-28653. doi:10.1021/acs.jpcc.5b09034

31. Makaremi, M.; Mortazavi, B.; Singh, C. V. J. Phys. Chem. C 2017, 121, 18575-18583. doi:10.1021/acs.jpcc.7b04511

32. Santosh, K. C.; Longo, R. C.; Addou, R.; Wallace, R. M.; Cho, K. Nanotechnology 2014, 25, 375703. doi:10.1088/0957-4484/25/37/375703

33. Ma, Q.; Odenthal, P. M.; Mann, J.; Le, D.; Wang, C. S.; Zhu, Y.; Chen, T.; Sun, D.; Yamaguchi, K.; Tran, T.; Wurch, M.; McKinley, J. L.; Wyrick, J.; Magnone, K.; Heinz, T. F.; Rahman, T. S.; Kawakami, R.; Bartels, L. J. Phys.: Condens. Matter 2013, 25, 252201. doi:10.1088/0953-8984/25/25/252201

34. Kresse, G.; Furthmüller, J. Phys. Rev. B 1996, 54, 11169-11186. doi:10.1103/physrevb.54.11169

35. Perdew, J. P.; Burke, K.; Ernzerhof, M. Phys. Rev. Lett. 1996, 77, 3865-3868. doi:10.1103/physrevlett.77.3865

36. Blöchl, P. E. Phys. Rev. B 1994, 50, 17953-17979. doi:10.1103/physrevb.50.17953

37. Materials Project. Materials Data on $\mathrm{MoS}_{2}$ (SG:194). https://materialsproject.org/materials/mp-2815/ (accessed Feb 10, 2020). doi:10.17188/1202268

38. Hjorth Larsen, A.; Mortensen, J. J.; Blomqvist, J.; Castelli, I. E.; Christensen, R.; Dulak, M.; Friis, J.; Groves, M. N.; Hammer, B.; Hargus, C.; Hermes, E. D.; Jennings, P. C.; Jensen, P. B.; Kermode, J.; Kitchin, J. R.; Kolsbjerg, E. L.; Kubal, J.; Kaasbjerg, K.; Lysgaard, S.; Maronsson, J. B.; Maxson, T.; Olsen, T.; Pastewka, L.; Peterson, A.; Rostgaard, C.; Schiotz, J.; Schütt, O.; Strange, M.; Thygesen, K. S.; Vegge, T.; Vilhelmsen, L.; Walter, M.; Zeng, Z.; Jacobsen, K. W. J. Phys.: Condens. Matter 2017, 29, 273002. doi:10.1088/1361-648x/aa680e

39. Henkelman, G.; Arnaldsson, A.; Jónsson, H. Comput. Mater. Sci. 2006, 36, 354-360. doi:10.1016/j.commatsci.2005.04.010

40. Sanville, E.; Kenny, S. D.; Smith, R.; Henkelman, G. J. Comput. Chem. 2007, 28, 899-908. doi:10.1002/jcc.20575

41. Materials Project. Materials Data on CuS (SG:63). https://materialsproject.org/materials/mp-555599/ (accessed Feb 10, 2020). doi:10.17188/1268899

\section{License and Terms}

This is an Open Access article under the terms of the Creative Commons Attribution License (https://creativecommons.org/licenses/by/4.0). Please note that the reuse, redistribution and reproduction in particular requires that the authors and source are credited.

The license is subject to the Beilstein Journal of Nanotechnology terms and conditions: (https://www.beilstein-journals.org/bjnano)

The definitive version of this article is the electronic one which can be found at:

doi:10.3762/bjnano.11.30 